\title{
Upgrading the Fermentation Process of Zhejiang Rosy Vinegar by Purebred Microorganisms
}

\author{
Yujian Jiang ${ }^{1,2}$, Sen Lin ${ }^{1}$, Lei Zhang ${ }^{1,2}$, Ping Yu ${ }^{1,2^{*}}$ \\ ${ }^{1}$ College of Food Science and Biotechnology, Zhejiang Gongshang University, Hangzhou, China \\ ${ }^{2}$ Food Safety Key Laboratory of Zhejiang Province, Hangzhou, China \\ Email: *yup9202@yahoo.com.cn
}

Received March 8, 2013; revised April 8, 2013; accepted May 8, 2013

Copyright (C) 2013 Yujian Jiang et al. This is an open access article distributed under the Creative Commons Attribution License, which permits unrestricted use, distribution, and reproduction in any medium, provided the original work is properly cited.

\begin{abstract}
Purebred microorganisms were employed to upgrade the fermentation process of Zhejiang rosy vinegar. The fermentation cycle was greatly shorten from 5 months to $72 \mathrm{~d}$. The transformation rate of raw materials was increased from 1:4.5 in the traditional fermentation to $1: 5$ or more in the upgraded fermentation. The content of organic acids in the traditional vinegar (TRV), the upgraded vinegar (UPV) and the submerged fermentation vinegar (SFV) were also investigated by HPLC. No significant difference was found regarding the proportion of phenylethanol to the total volatile components in UPV $(7.47 \% \pm 0.00324 \%)$ and TRV $(7.23 \% \pm 0.00329 \%)$, but it was significantly higher than that in SFV $(2.26 \% \pm 0.00143 \%)$. This study provides deep insight into upgrading the fermentation process of Zhejiang rosy vinegar by purebred microorganisms.
\end{abstract}

Keywords: Zhejiang Rosy Vinegar; Purebred Microorganisms; Fermentation Process; Organic Acids; Volatile Components

\section{Introduction}

Vinegar is a solution of acetic acid, mainly prepared by a three-stage fermentation process using rice or the malted barley as raw material [1]: the degradation of starch from the raw material to fermentable sugars by mould, the conversion of fermentable sugars to ethanol by yeast, and the oxidation of ethanol to acetic acid by bacteria [2]. Rosy vinegar is very popular in the Southeast area of China for its special color and flavor. The traditional fermentation process of the rosy vinegar is shown in Figure 1. Starch from rice was fermented by wild microorganisms naturally falling into the fermentation container during fermentation. Because this is a natural process, the quality of the rosy vinegar was greatly influenced by different environmental factors, and hence the fermentation process has to be undergone in some particular seasons [3]. This also means that the quality of the rosy vinegar is not stable and the fermentation cycle is prolonged. Therefore, an increasing attention has been given to upgrade the traditional fermentation process of Zhejiang rosy vinegar in recent ten years.

Endogenous enzymes, bacteria, yeast and mould con-

${ }^{*}$ Corresponding author. tribute to the preparation of a great variety of products in the traditional fermentation [4]. In order to upgrade the fermentation process of Zhejiang rosy vinegar, purebred microorganisms were employed and fermentation parameters were optimized to further promote the growth of these microorganisms. The typical characters of the traditional vinegar (TRV) and the upgraded one (UPV) were also compared.

\section{Materials and Methods}

\subsection{Microorganisms and Reagents}

Two amylase-producing strains (Aspergillus niger AS3.4309 and Rhizopus) that can convert rice starch to fermentative sugars were purchased from the Shanghai Traditional Fermentation Factory, China. Saccharomyces cerevisiae $\mathrm{K}$ (providing alcohol dehydrogenase), Saccharomyces AS2.202 and Saccharomyces AS2.1182 (providing esterases for wine fragrance-strengthening) were used at the fermentation stage of alcohol and purchased from the Shanghai Traditional Fermentation Factory, China. Acetobacter AB3 that can convert alcohol to acetic acid was isolated from the leavening from the traditional process and named the acetic acid bacterium. 


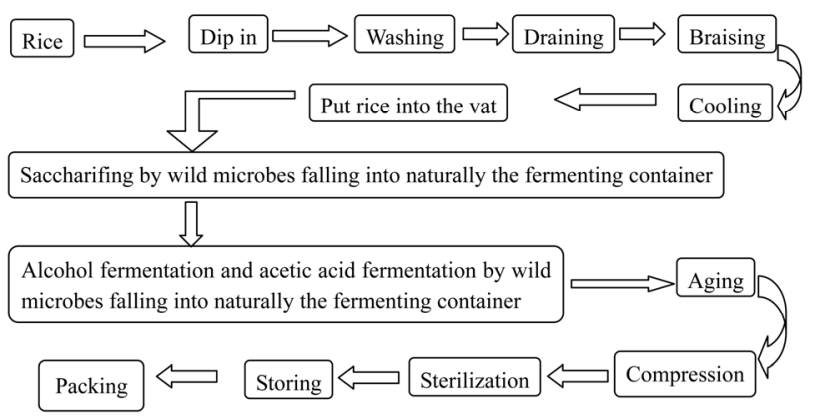

Figure 1. The traditional fermentation technology of Zhejiang rosy vinegar.

The seeds of these microorganisms were cultured in the appropriate cultural media as described by Haruta et al. [5] and kept in our laboratory until use.

Glucose, sodium hydroxide, methylene blue, sodium potassium titrate, lactic acid, acetic acid, oxalic acid, tartaric acid, formic acid, malic acid, citric acid, succinic acid, propionic acid and ammonium phosphate were purchased from the Hangzhou Huipu Chemical Co. Ltd., China. All other chemicals are analytical grade and used as the routine method.

\subsection{Purebred Microbial Fermentation}

The following materials were adequately mixed in a 500 $\mathrm{L}$ vat: the steamed rice (approximate $50 \%$ of the moisture content), $200 \mathrm{~kg}$; Asp. niger AS3.4309, $7 \mathrm{~kg}$ and Rhizopus, $9 \mathrm{~kg}$. The inlet of vat was covered with the grass cover. After cultivation for $7 \mathrm{~d}$, the vat was filled with the sterilized water. $25 \mathrm{~L}$ of the mixture including $S$. cerevisiae K, Saccharomyces AS2.202 and AS2.1182 with the ratio of $8: 1: 1$ was added to the fermentation liquid. The fermentation temperature was controlled at $30^{\circ} \mathrm{C}$. After $12 \mathrm{~d}, 30 \mathrm{~L}$ of Acetobacter AB3 was added to the fermentation liquid.

\subsection{Evaluation of the Color Degree}

A quantitative method for the evaluation of the color degree of the rosy vinegar has been established as follows: the sample was diluted by 2 -fold and then centrifuged at $5000 \mathrm{rpm}$ for $30 \mathrm{~min}$, and then the supernatant was used to measure the optical absorbance values at 460 , 510,530 and $610 \mathrm{~nm}$. The values of $\mathrm{OD}_{460} / \mathrm{OD}_{610}$, $\mathrm{OD}_{510} / \mathrm{OD}_{610}, \mathrm{OD}_{530} / \mathrm{OD}_{610}$ and $\mathrm{OD}_{610} \times 20000 / 0.076$ were defined as the yellow index, the red index, the rosy index and the color ratio, respectively [6].

\subsection{Organic Acids}

The content of organic acids in both the upgraded rosy vinegar sample and the traditional one was determined by Agilent 1100 HPLC with UV detector $(210 \mathrm{~nm})$ and a non-polar column Zorbax 300SB-C18 $\mu \mathrm{m} \times 4.6 \mathrm{~mm} \times$
$250 \mathrm{~mm} .5 \mathrm{~g} / \mathrm{L}\left(\mathrm{NH}_{4}\right)_{2} \mathrm{HPO}_{4}(\mathrm{pH}=2.90)$ was used as liquid phase. The column temperature was $30^{\circ} \mathrm{C}$, the flow of liquid phase was $0.8 \mathrm{~mL} / \mathrm{min}$ and the inject volume was $10 \mu \mathrm{L}$ [7].

\subsection{Volatile Components}

The HS-SPME analysis was performed with the Agilent 7890 gas chromatograph coupled with a 5975 mass-selective detector to analyze the volatile components in the vinegar. $3 \mathrm{~mL}$ of the vinegar sample was transferred by a calibrand syringe to a $10 \mathrm{~mL}$ glass vial and add $2 \mathrm{~g}$ of $\mathrm{NaCl}$ to obtain volatile components, and then the vial was capped with a PTFE-faced silicone septum and shaken by a magnetic stirrer to obtain a homogeneous mixture. The sample was maintained at $50^{\circ} \mathrm{C}$ and the fiber was inserted through the vial septum and exposed to the sample headspace for $40 \mathrm{~min}$ to perform the extraction. The fiber was inserted into a GC injector for $3 \mathrm{~min}$ for adsorption $[8,9]$.

The separation was performed using an innowax capillary colum (J\&W Scientific, Folsom, CA, USA), $30 \mathrm{~m}$ $\times 0.25 \mathrm{~mm}$, with a $0.25 \mu \mathrm{m}$ coating. The splitless injection mold was chosen and the injector temperature was set as $240^{\circ} \mathrm{C}$. Ultrahigh-purity helium was used as the carrier gas at the flow rate of $1.1 \mathrm{~mL} / \mathrm{min}$. The oven temperature was programmed from $40^{\circ} \mathrm{C}$ (maintained for $20 \mathrm{~min}$ ) to $100^{\circ} \mathrm{C}$ at a rate of $5{ }^{\circ} \mathrm{C} / \mathrm{min}$ and finally raised to $210^{\circ} \mathrm{C}$ at $3^{\circ} \mathrm{C} / \mathrm{min}$. The final electron beam impact spectra were recorded in a $30-450$ amu range at $70 \mathrm{eV}$ ionization energy $[10,11]$.

\subsection{Statistics Analysis}

The statistics analysis of data was carried out using the Origin 8.0 Software. A " $p<0.05$ " was considered to be statistically significant.

\section{Results and Discussion}

\subsection{Changes in the Parameters during the Fermentation Processes}

The changes in the alcohol degree and the glucose concentration at alcohol fermentation stage are shown in Figure 2(a). The lag phenomenon of the alcohol fermentation was observed and the glucose concentration decreased to $0.1 \mathrm{~g} / 100 \mathrm{~mL}$ and maintained at a constant level until the fermentation finished. The alcohol degree was observed to increase continuously. The changes in the total organic acids and the alcohol degree at acetic acid fermentation stage are shown in Figures 2(b), respectively. The total organic acids and the alcohol degree increased simultaneously from 5 to $8 \mathrm{~d}$. The fermentation cycle was greatly shorten from 5 months using the traditional fermentation technology to $72 \mathrm{~d}$ using the 


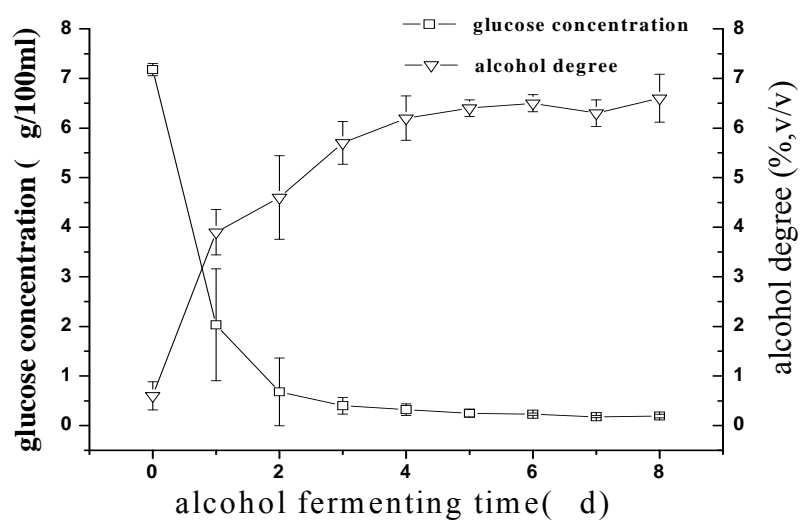

(a)

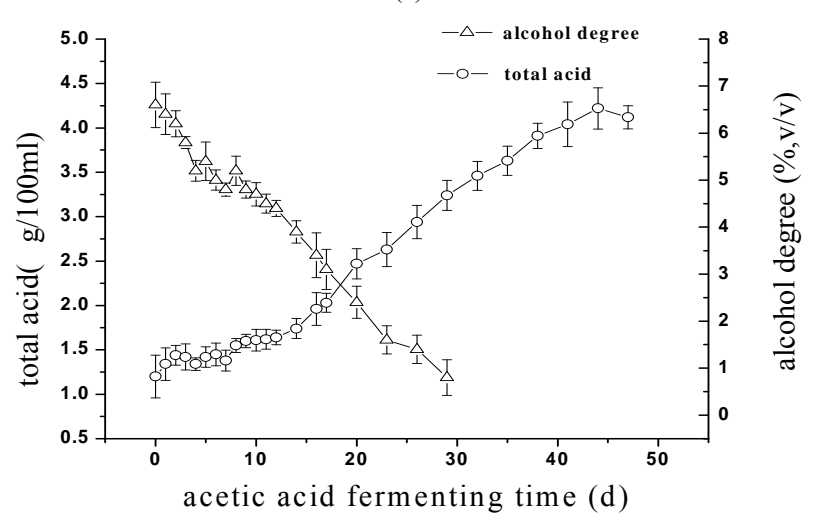

(b)

Figure 2. The changes in some parameters in the fermentation processes of the traditional rosy vinegar and the upgraded one. (a) Changes in the glucose concentration and the alcohol degree at the alcohol fermentation stage; (b) Changes in the total organic acids and the alcohol degree at the acetic acid stage.

pure microbial fermentation technology. Furthermore, a much higher transformation rate of raw materials (1:5.5 or more) could be achieved using the pure microbial fermentation technology. Thus, the rosy vinegar can be produced several times throughout a whole year compared to the traditional technology that it was only produced in some particular seasons.

\subsection{Color Degree}

The difference of the color degree between the traditional rosy vinegar and the upgraded one was investigated and the results are shown in Figures 3(a) and (b). Compared to the traditional rosy vinegar, the upgraded one had much higher yellow index, red index, rosy index and lower color ratio. A $t$-test was performed to check the difference among them. As shown in Table 1, a signifycance deference was observed $(p<0.05)$.

\subsection{Organic Acids}

The type and content of organic acids in TRV, UPV and

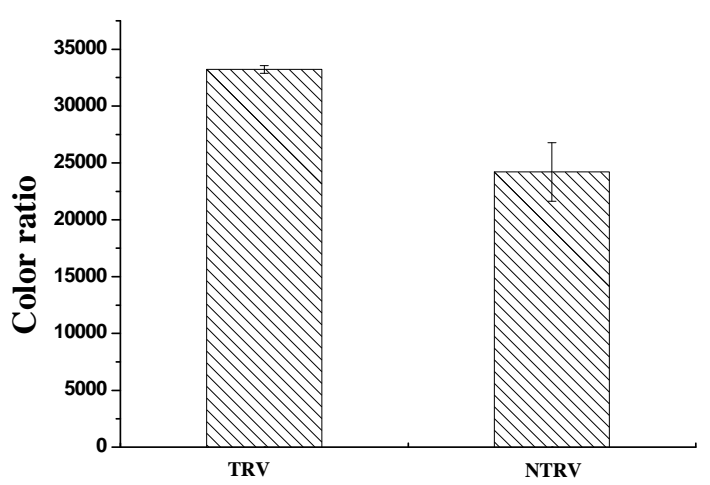

(a)

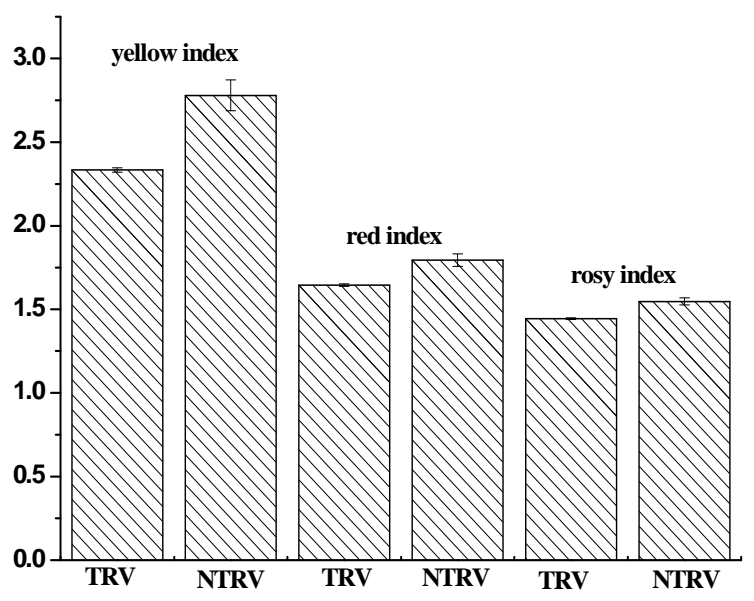

(b)

Figure 3. Evaluation of the color degree between the traditional rosy vinegar and the upgraded one.

Table 1. $t$-Test of the color degree.

\begin{tabular}{cccc}
\hline & $\mathrm{t}$ & $\mathrm{t}(0.05,2)$ & Significance $(p<0.05)$ \\
\hline Color ratio & 7.39 & 4.30 & $\mathrm{a}^{*}$ \\
Yellow index & 10.12 & 4.30 & $*$ \\
Red index & 8.24 & 4.30 & $*$ \\
Rosy index & 9.88 & 4.30 & $*$ \\
\hline
\end{tabular}

$\mathrm{a}^{*}$ means statistically significant $(p<0.05)$.

SFV were studied by HPLC and the result is shown in Table 2. Organic acids including oxalic acid, tartaric acid, formic acid, malic acid, lactic acid, citric acid, succinic acid, propanoic acid and acetic acid, could be detected in TRV and UPV, whereas only eight of them could be found in SFV. Compared to SFV, the other two vinegars had a higher content of organic acids, but no significant difference among them was found $(p>0.05)$. A much higher proportion of organic acids (except for acetic acid) to the total ones were observed in UPV $(27.48 \% \pm 0.027 \%)$ or TRV $(31.89 \% \pm 0.050 \%)$ than in SFV $(2.09 \% \pm 0.002 \%)$. This means that UPV or TRV has a much more harmonious taste than SFV. 


\subsection{Volatile Components}

The volatile components in TRV, UPV and SFV were studied by HS-GC-MS and the result is shown in Table 3. Compared to SFV, the major components of volatile fla- vors in TRV and UPV were identified as alcohols, acids, aldehydes and ketones. However, no significant difference in the categories of volatile components were found in the two vinegars. Phenylethanol that can endows the

Table 2. The content of organic acids in UPV, TRV and SFV (g/100 mL).

\begin{tabular}{|c|c|c|c|}
\hline & UPV & TRV & SFV \\
\hline Oxalic acid & $0.087 \pm 0.008$ & $0.061 \pm 0.005$ & ND \\
\hline Tartaric acid & $0.284 \pm 0.027$ & $0.284 \pm 0.007$ & ND \\
\hline Formic acid & $0.005 \pm 0.01$ & $0.263 \pm 0.010$ & $0.136 \pm 0.061$ \\
\hline Malic acid & $0.112 \pm 0.005$ & $0.084 \pm 0.007$ & $0.022 \pm 0.007$ \\
\hline Lactic acid & $0.656 \pm 0.025$ & $0.596 \pm 0.033$ & $0.698 \pm 0.059$ \\
\hline Citric acid & $0.053 \pm 0.004$ & $0.041 \pm 0.001$ & $0.180 \pm 0.026$ \\
\hline Succinic acid & $0.135 \pm 0.008$ & $0.110 \pm 0.009$ & $0.016 \pm 0.004$ \\
\hline Propanoic acid & $0.389 \pm 0.198$ & $0.560 \pm 0.023$ & $0.015 \pm 0.001$ \\
\hline Acetic acid & $4.541 \pm 0.033$ & $4.267 \pm 0.059$ & $5.372 \pm 0.11$ \\
\hline Proportion of organic acids to the total ones & $27.48 \% \pm 0.027 \%$ & $31.89 \% \pm 0.050 \%$ & $2.09 \% \pm 0.002 \%$ \\
\hline
\end{tabular}

ND: No Detect.

Table 3. Volatile components in UPV, TRV and SFV.

\begin{tabular}{|c|c|c|c|}
\hline & \multicolumn{3}{|c|}{ Relative content (\%) } \\
\hline & UPV & TRV & SFV \\
\hline Ethanol & $2.72 \% \pm 0.00211 \%$ & $2.40 \% \pm 0.00045 \%$ & $1.48 \% \pm 0.00087 \%$ \\
\hline 3-Methy-1-butanol & $0.94 \% \pm 0.00199 \%$ & $1.04 \% \pm 0.0008 \%$ & $1.24 \% \pm 0.0004 \%$ \\
\hline 2,6-Dimethy heptanol & $0.26 \% \pm 0.00055 \%$ & $0.23 \% \pm 0.00046 \%$ & ND \\
\hline Phenylethanol & $7.47 \% \pm 0.00324 \%$ & $7.23 \% \pm 0.00329 \%$ & $2.26 \% \pm 0.00143 \%$ \\
\hline 2-(2-Ethoxyethoxy)-ethanol & $1.01 \% \pm 0.00046 \%$ & $0.95 \% \pm 0.0007 \%$ & $0.54 \% \pm 0.00024 \%$ \\
\hline $\mathrm{N}, \mathrm{N}$-dimethyl-propanamide & $2.28 \% \pm 0.00051 \%$ & $1.13 \% \pm 0.00103 \%$ & ND \\
\hline N-ethyl-acetamide & $0.13 \% \pm 0.00013 \%$ & ND & $0.58 \% \pm 0.00035 \%$ \\
\hline N-ethyl-propanamide & $0.30 \% \pm 0.00079 \%$ & $0.24 \% \pm 0.00058 \%$ & ND \\
\hline 2,4,5-Trimethyl-1,3-dioxolane & $2.31 \% \pm 0.00108 \%$ & $2.21 \% \pm 0.00165 \%$ & ND \\
\hline 3-Hydroxy-2-butanone & $0.24 \% \pm 0.00018 \%$ & $0.20 \% \pm 0.00025 \%$ & $8.20 \% \pm 0.00141 \%$ \\
\hline 2-Pentanone & $2.51 \% \pm 0.00426 \%$ & $2.10 \% \pm 0.00118 \%$ & $0.53 \% \pm 0.00043 \%$ \\
\hline 2-Methyl-propanoic acid & $0.97 \% \pm 0.00062 \%$ & $0.75 \% \pm 0.00068 \%$ & $0.55 \% \pm 0.0003 \%$ \\
\hline 3-Methyl-butanoic acid & $0.80 \% \pm 0.00137 \%$ & $0.85 \% \pm 0.0007 \%$ & $1.71 \% \pm 0.0003 \%$ \\
\hline Acetic acid & $63.67 \% \pm 0.00509 \%$ & $69.32 \% \pm 0.0157 \%$ & $76.67 \% \pm 0.01456 \%$ \\
\hline Octanoic acid & $0.85 \% \pm 0.00159 \%$ & $0.28 \% \pm 0.00052 \%$ & $0.24 \% \pm 0.0002 \%$ \\
\hline Benzaldehyde & $3.18 \% \pm 0.00303 \%$ & $1.27 \% \pm 0.0003 \%$ & $0.48 \% \pm 0.0003 \%$ \\
\hline Furfural & $1.09 \% \pm 0.00201 \%$ & $1.12 \% \pm 0.00253 \%$ & $0.63 \% \pm 0.00026 \%$ \\
\hline 4-Ethyl-2-methoxy-phenol & $0.59 \% \pm 0.00034 \%$ & $0.58 \% \pm 0.00035 \%$ & ND \\
\hline Ethyl acetate & $1.16 \% \pm 0.00097 \%$ & $1.38 \% \pm 0.00035 \%$ & $1.33 \% \pm 0.00037 \%$ \\
\hline Butanedioic acid diethyl ester & $0.16 \% \pm 0.00022 \%$ & ND & ND \\
\hline Propanoic acid-2-phenylethyl ester & $0.53 \% \pm 0.00069 \%$ & $2.24 \% \pm 0.00189 \%$ & $2.05 \% \pm 0.00045 \%$ \\
\hline Benzeneacetic acid-2-propenyl ester & $0.46 \% \pm 0.00072 \%$ & $0.43 \% \pm 0.00062 \%$ & ND \\
\hline Isobutyl isothiocyanate & $4.75 \% \pm 0.000353 \%$ & $3.02 \% \pm 0.000224 \%$ & ND \\
\hline
\end{tabular}

ND: No Detect. 
vinegar with a pleasure fragrance should be specially concerned. It contributes greatly to the vinegar flavor because of the relatively lower threshold value (1000 ppb in water) [12]. No great difference could be found about the proportion of phenylethanol to the total volatile components between UPV $(7.47 \% \pm 0.00324 \%)$ and TRV $(7.23 \% \pm 0.00329 \%)$, but they were significantly higher than that in SFV $(2.26 \% \pm 0.00143 \%)$. The great difference could be observed on the proportion of acetic acid to the total volatile components among UPV $(63.67 \% \pm$ $0.00509 \%)$, TRV $(69.32 \% \pm 0.0157 \%)$ and SFV $(76.67 \%$ $\pm 0.01456 \%$ ) and the proportion of acetic acid to the total volatile components in UPV was much lower than that in TRV and SFV. This means a much less pungent savor from UPV than those from TRV or SFV.

\section{Conclusion}

The results of the present study demonstrate that it can be achieved to produce Zhejiang rosy vinegar by the pure microbial fermentation technology. With this technology, the fermentation cycle was reduced from 5 months using the traditional fermentation to $72 \mathrm{~d}$, and could gain a much higher transformation rate of raw materials (1:5 or more). There was some difference on the color degree between TRV and UPV, but no significant difference on the content of organic acids and volatile components which contribute greatly to the flavor of vinegar was observed. This study provides deep insight into the largescale industrial production of Zhejiang rosy vinegar by pure microbial strains.

\section{Acknowledgements}

Authors thank Zhengyi Qian and Linan Zhou for their help in providing raw materials for this study. We also thank Zhijiang Zhang, Wei Feng and Yue Liu for useful suggestions about experiments. This work was supported by the Zhejiang Province Science and Technology Committee (No. 2006C32013).

\section{REFERENCES}

[1] L. Giordano, R. Calabrese, E. Davoli and D. Rotilia, "Quantitive Analysis of 2-Furfural and 5-Methylfurfural in Different Italian Vinegar by Headspace Solid-Phase Microextraction Coupled to Gas Chromatography-Mass Spectrometry Using Isotope Dilution," Journal of Chromatography A, Vol. 1017, No. 1-2, 2003, pp. 141-149. doi:10.1016/j.chroma.2003.08.029

[2] W. Tesfaye, M. L. Morales, M. C. Garca-Parrilla and A. M. Troncoso, "Wine Vinegar: Technology, Authenticity and Quality Evaluation," Trends in Food Science and Technology, Vol. 13, No. 1, 2002, pp. 12-21.
doi:10.1016/S0924-2244(02)00023-7

[3] J. G. Wang, "Preliminary Study on the Traditional Technology of Zhejiang Rosy Vinegar," China Brewing, Vol. 6, No. 5, 2004, pp. 23-26.

[4] W. P. Hammes, M. J. Brandt, K. L. Francis, J. Rosenheim, M. F. H. Seitter and S. A. Vogelmann, "Microbial Ecology of Cereal Fermentations," Trends in Food Science and Technology, Vol. 16, No. 1-3, 2005, pp. 4-11. doi:10.1016/j.tifs.2004.02.010

[5] S. Haruta, S. Ueno, I. Egawa, K. Hashiguchi, A. Fujii, M. Nagano, M. Ishii and Y. Igarashi, "Succession of Bacterial and Fungal Communities during a Traditional Pot Fermentation of Rice Vinegar Assessed by PCR-Mediated Denaturing Gradient Gel Electrophoresis," International Journal of Food Microbiology, Vol. 109, No. 1-2, 2006, pp. 79-87. doi:10.1016/j.ijfoodmicro.2006.01.015

[6] F. López, P. Pescador, C. Güell, M. L. Morales, M. C. García-Parrilla and A. M. Troncoso, "Industrial Vinegar Clarification by Cross-Flow Microfiltration: Effect on Colour and Polyphenol Content," Journal of Food Engineering, Vol. 68, No. 1, 2005, pp. 133-136. doi:10.1016/i.jfoodeng.2004.05.021

[7] M. Cocchi, C. Durante, G. Foca, D. Manzini, A. Marchetti and A. Ulrici, "Application of a Wavelet-Based Algorithm on HS-SPME/GC Signals for the Classification of Balsamic Vinegars," Chemometrics and Intelligent Laboratory Systems, Vol. 71, No. 2, 2004, pp. 129-140. doi:10.1016/j.chemolab.2004.01.004

[8] M. Cocchi, C. Durante, M. Grandi, P. Lambertini, D. Manzini and A. Marchetti, "Simultaneous Determination of Sugars and Organic Acids in Aged Vinegars and Chemometric Data Analysis," Talanta, Vol. 69, No. 5, 2006, pp. 1166-1175. doi:10.1016/j.talanta.2005.12.032

[9] C. Pizarro, I. Esteban-Diez and C. Saenz-Gonzalez, "Vinegar Classfication Based on Feature Extraction and Selection from Headspace Solid-Phase Microextraction/Gas Chromatography Volatile Analysises: A Feasibility Study," Analytica Chimica Acta, Vol. 608, No. 1, 2008, pp. 38-47. doi:10.1016/j.aca.2007.12.006

[10] M. J. Sáiz-Abajo, J. M. González-Sáiz and C. Pizarro, "Multi-Objective Optimisation Strategy Based on Desirability Functions Used for Chromatographic Separation and Quantification of L-Proline and Organic Acids in Vinegar," Analytica Chimica Acta, Vol. 528, No. 1, 2005, pp. 63-76. doi:10.1016/j.aca.2004.06.027

[11] M. J. Sáiz-Abajo, J. M. González-Sáiz and C. Pizarro, "Prediction of Organic Acids and Other Quality Parameters of Wine Vinegar by Near-Infrared Spectroscopy. A Feasibility Study," Food Chemistry, Vol. 99, No. 3, 2006, pp. 615-621. doi:10.1016/j.foodchem.2005.08.006

[12] H. Song and K. R. Cadwallader, "Aroma Components of American Country Ham," Journal of Food Science, Vol. 73, No. 1, 2008, pp. c29-c35. doi:10.1111/j.1750-3841.2007.00593.x 